\title{
A pilot study on a potential relationship between leg bone length and sprint performance in sprinters; are there any event-related differences in 100-m and 400-m sprints?
}

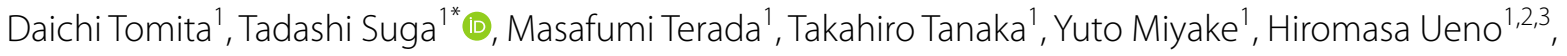 \\ Mitsuo Otsuka', Akinori Nagano ${ }^{1}$ and Tadao Isaka ${ }^{1}$
}

\begin{abstract}
Objective: This study examined the relationship between leg bone length and sprint performance in sprinters. The leg bone lengths in 28 100-m specialized sprinters and 28 400-m specialized sprinters were measured using magnetic resonance imaging. The lengths of the upper and lower leg bones were assessed by calculating the lengths of the femur and tibia, respectively. To minimize differences in body size among participants, both bone lengths were normalized to body height. The ratio of the tibial length to femoral length was calculated to evaluate the interaction between the lengths of the upper and lower leg bones. International Amateur Athletic Federation (IAAF) scores, based on the personal best times of the sprinters in each group were used as parameters for sprint performance.

Results: There were no significant correlations between absolute and relative lengths of the femur and tibia and IAAF scores in both 100-m and 400-m sprinters. By contrast, the ratio of the tibial length to femoral length correlated significantly with IAAF score in 400-m sprinters $(r=0.445, P=0.018)$, but not 100-m sprinters. These findings suggest that the leg bone lengths may play an important role in achieving superior long sprint performance in 400-m specialized sprinters.
\end{abstract}

Keywords: Femoral length, Tibial length, Step frequency, Step length, Magnetic resonance imaging

\section{Introduction}

Some morphological factors are associated with superior sprint performance in sprinters [1-7]. Sprint velocity is expressed as the product of step length and frequency [8], suggesting that morphological factors regulating the two sprint variables may play important roles in achieving superior sprint performance in sprinters. The leg length

\footnotetext{
*Correspondence: t-suga@fc.ritsumei.ac.jp

1 Faculty of Sport and Health Science, Ritsumeikan University, 1-1-1

Nojihigashi, Kusatsu, Shiga 525-8577, Japan

Full list of author information is available at the end of the article
}

is a major morphological factor regulating step length [9, 10]; thus, longer leg may result in better sprint performance due to an increased step length during sprinting [11]. We and others previously found a positive relationship between leg length and running performance in endurance runners [12-14]. However, the effect of leg length on sprint performance in sprinters is still poorly understood.

Previous studies reported that step frequency may be a more important kinematic factor for superior sprint performance than step length [15-18]. Morin et al. [15] demonstrated a positive correlation between step frequency

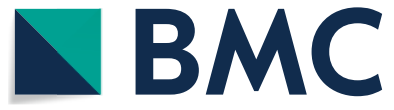

(c) The Author(s) 2020. This article is licensed under a Creative Commons Attribution 4.0 International License, which permits use, sharing, adaptation, distribution and reproduction in any medium or format, as long as you give appropriate credit to the original author(s) and the source, provide a link to the Creative Commons licence, and indicate if changes were made. The images or other third party material in this article are included in the article's Creative Commons licence, unless indicated otherwise in a credit line to the material. If material is not included in the article's Creative Commons licence and your intended use is not permitted by statutory regulation or exceeds the permitted use, you will need to obtain permission directly from the copyright holder. To view a copy of this licence, visit http://creativeco mmons.org/licenses/by/4.0/. The Creative Commons Public Domain Dedication waiver (http://creativecommons.org/publicdomain/ zero/1.0/) applies to the data made available in this article, unless otherwise stated in a credit line to the data. 
and sprint velocity during 100-m sprinting; however, no such correlation was obtained with step length. Hobara et al. [16] reported that step frequency correlated with vertical stiffness (i.e., the ratio of peak vertical force and vertical center of mass displacement), which is positively related to sprint velocity, during 400-m sprinting. However, no such correlation was also obtained with step length. Therefore, morphological factors regulating step frequency may be more important in achieving superior sprint performance than that regulating step length.

Physiological factors, including anaerobic capacity and fatigue resistance, are known to play important roles in achieving superior long sprint performance during 400-m sprinting $[19,20]$. Utilizing these physiological capacities during a 400-m sprint can be mitigated by sprinting economically. The leg is swung forward with the knee bent during the swing phase while sprinting. Based on this leg behavior, an increased ratio of the lower leg length relative to the upper leg length (i.e., thigh length) may reduce the leg's moment of inertia and positive work done by the hip flexors during the swing phase, potentially due to decreased leg mass, since the lower leg has less mass than that of the upper leg [21]. Therefore, this favorable morphology may be useful in enhancing step frequency and performing economical sprinting. Considering these findings, we hypothesized that a higher ratio of the lower leg length to upper leg length would be positively related to better sprint performance in sprinters, especially in 400-m specialized sprinters.

Generally, the leg length is measured with an anthropometrical technique, which is performed manually using a tape measure. Nevertheless, this measurement may have a technical limitation due to possible ambiguity in measuring the leg length. Compared to this general anthropometrical measurement, magnetic resonance imaging (MRI) is more appropriate for morphological measurements [1-7, 14, 22], including bone length measurements $[4,5,14,22]$. To test our hypothesis with higher precision, we used MRI to examine the relationships between leg bone length variables and sprint performance in both 100-m and 400-m specialized sprinters.

\section{Main text Methods \\ Subjects}

Fifty-six male sprinters participated in this study. Of those, 28 sprinters (age: $20.3 \pm 1.6$ years) specialized in the $100-\mathrm{m}$ race and 28 sprinters (age: $20.1 \pm 1.4$ years) specialized in the 400-m race. Sprinters in each group were well-trained and competed regularly at their distances. Mean personal best time for the 100-m specialized sprinters was $11.05 \pm 0.33 \mathrm{~s}$. Mean personal best time for the 400-m specialized sprinters was $49.96 \pm$
1.63 s. Mean International Amateur Athletic Federation scores (an interindividual score for the comparison of competitive performances in different events) based on these personal best time were used as parameters for sprint performance in each group. Informed written consent was obtained from all participants. This study was approved by the Ethics Committee of Ritsumeikan University.

\section{MRI measurements}

Representative images for calculating the leg bone lengths on magnetic resonance imaging (MRI) are shown in Fig. 1. The MRI measurement has been previously described [14]. The analyses for measuring the lengths of the leg bones were conducted using image analysis software (OsiriX Version 5.6; OsiriX Foundation, Geneva, Switzerland). The lengths of the femur and tibia were calculated from coronal images for the leg, respectively. The femoral length was calculated as the distance between the tip of the greater trochanter and the distal end of the lateral condyle of the femur. The tibial length was calculated as the distance between the proximal end of the lateral condyle and the distal inferior surface of the tibia. The total length of the femur and tibia was calculated to assess the overall leg bone length. To minimize differences in body size among participants, these both lengths were normalized to body height. The ratio of the tibial length to femoral length was calculated to evaluate

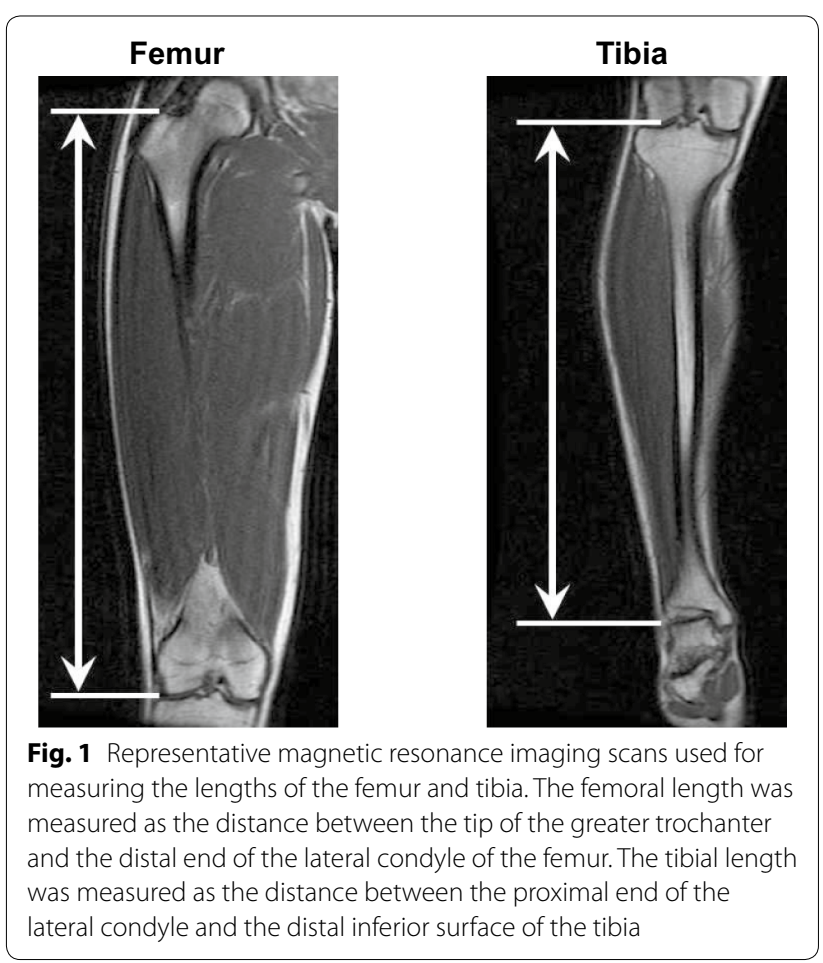


interaction between the lengths of the upper and lower leg bones. The reproducibility of the leg bone length has been noted in our previous study [14].

\section{Statistical analysis}

The data are presented as the mean $\pm \mathrm{SD}$. Comparisons of groups were performed using an unpaired $t$-test. Relationship between variables was evaluated using a Pearson's product moment correlation. Statistical significance was defined at $P<0.05$. All statistical analyses were conducted using IBM SPSS software (version 19.0; International Business Machines Corp, NY, USA).

\section{Results}

IAAF scores did not differ significantly between $100-\mathrm{m}$ specialized sprinters and $400-\mathrm{m}$ specialized sprinters (873 \pm 97 and $863 \pm 97)$.

Physical characteristics and leg bone length variables of the 100-m and 400-m sprinters are summarized in Table 1. Physical characteristics (i.e., body height, body weight, and body mass index) did not differ between 100-m and 400-m sprinters. Additionally, all leg bone length variables did not differ between the two groups.

Coefficient correlations between leg bone length variables and IAAF score of the $100-\mathrm{m}$ and $400-\mathrm{m}$ sprinters are summarized in Table 2. Absolute and relative lengths of the femur and tibia did not correlate with IAAF scores in both $100-\mathrm{m}$ and $400-\mathrm{m}$ sprinters. Absolute and relative total lengths of the femur and tibia also did not correlate with IAAF Score in the two groups. By contrast, the ratio of the tibia length to femur length correlated with IAAF score in 400-m sprinters, but not in 100-m sprinters.

\section{Discussion}

The primary finding of this study was that a higher ratio of the tibia length to femoral length correlated with better IAAF score in 400-m sprinters, but not in 100-m sprinters. Maintaining a consistent step frequency during 400-m sprinting is required for achieving superior long sprint performance [16, 23]. Morphological factors may contribute to the maintenance of step frequency, potentially by sustaining economical sprinting $[5,6]$. The ratio between the leg bone lengths may be useful in reducing the leg's moment of inertia and the positive work of the hip flexors during the swing phase while sprinting. Thus, this favorable morphology may help achieve superior long sprint performance, potentially by maintaining step frequency and allowing for economical sprinting in 400-m specialized sprinters.

This study showed no correlation between the ratio of the tibia length to femur length and IAAF score in $100-\mathrm{m}$ sprinters. In general, superior $100-\mathrm{m}$ sprint performance may not require economical movement, because sprint velocity during $100-\mathrm{m}$ sprinting does not decrease significantly compared to that during 400-m sprinting [11, 24]. Furthermore, superior $100-\mathrm{m}$ sprint performance is related to greater ground reaction force during 100-m sprinting [15, 40]. An increase in the ground reaction force during $100-\mathrm{m}$ sprinting may be associated with greater sizes of some leg muscles because of the positive relationships between these muscle sizes and 100-m sprint performance $[1,3,7]$. In particular, previous studies determined that greater thigh muscles, including the quadriceps femoris and hamstring, correlated with better 100-m

Table 1 Physical characteristics and leg bone length variables in 100-m and 400-m specialized sprinters

\begin{tabular}{|c|c|c|c|c|c|}
\hline & 100-m sprinters & 400-m sprinters & $F$ & $P$ & Cohen's $d$ \\
\hline Body height, $\mathrm{cm}$ & $173.2 \pm 4.0$ & $172.4 \pm 4.1$ & 0.088 & 0.437 & 0.198 \\
\hline Body weight, kg & $64.6 \pm 5.2$ & $62.8 \pm 4.1$ & 1.462 & 0.173 & 0.384 \\
\hline Body mass index, $\mathrm{kg} / \mathrm{m}^{2}$ & $21.5 \pm 1.3$ & $21.1 \pm 0.9$ & 3.925 & 0.232 & 0.358 \\
\hline \multicolumn{6}{|l|}{ Leg bone length } \\
\hline Femur, mm & $432.0 \pm 15.6$ & $430.8 \pm v 12.2$ & 1.588 & 0.737 & 0.086 \\
\hline Tibia, mm & $359.7 \pm 14.7$ & $357.9 \pm 13.0$ & 1.678 & 0.620 & 0.130 \\
\hline \multicolumn{6}{|l|}{ Relative leg bone length } \\
\hline Femur, $\%$ of body height & $24.9 \pm 0.6$ & $25.0 \pm 0.4$ & 3.868 & 0.696 & 0.196 \\
\hline Tibia, \% of body height & $20.8 \pm 0.6$ & $20.8 \pm 0.6$ & 0.210 & 0.984 & 0.000 \\
\hline \multicolumn{6}{|l|}{ Total leg bone length } \\
\hline Femur + Tibia, mm & $791.7 \pm 29.5$ & $788.6 \pm 23.2$ & 2.311 & 0.663 & 0.117 \\
\hline \multicolumn{6}{|l|}{ Relative total leg bone length } \\
\hline Femur + Tibia, $\%$ of body height & $45.7 \pm 1.1$ & $45.7 \pm 0.8$ & 3.466 & 0.850 & 0.000 \\
\hline \multicolumn{6}{|l|}{ Ratio between leg bones } \\
\hline Tibia/Femur, mm/mm & $0.83 \pm 0.02$ & $0.83 \pm 0.02$ & 3.626 & 0.670 & 0.000 \\
\hline
\end{tabular}

Values are presented as Mean \pm SD 
Table 2 Correlation coefficients between leg bone length variables and sprint performance (International Amateur Athletic Federation score) in 100-m and 400-m specialized sprinters

\begin{tabular}{|c|c|c|c|c|}
\hline & \multicolumn{2}{|l|}{ 100-m sprinters } & \multicolumn{2}{|l|}{ 400-m sprinters } \\
\hline & $R$ [lower limit, upper limit] & $P$ value & $R$ [lower limit, upper limit] & $P$ value \\
\hline \multicolumn{5}{|l|}{ Leg bone length } \\
\hline Femur & $-0.166[-0.508,0.221]$ & 0.399 & $0.007[-0.367,0.379]$ & 0.970 \\
\hline Tibia & $-0.173[-0.513,0.214]$ & 0.380 & $0.336[-0.042,0.630]$ & 0.081 \\
\hline \multicolumn{5}{|c|}{ Relative leg bone length } \\
\hline Femur & $0.004[-0.370,0.377]$ & 0.983 & $-0.273[-0.586,0.111]$ & 0.160 \\
\hline Tibia & $-0.036[-0.404,0.342]$ & 0.857 & $0.257[-0.128,0.575]$ & 0.187 \\
\hline \multicolumn{5}{|l|}{ Total bone length } \\
\hline Femur + Tibia & $-0.174[-0.514,0.213]$ & 0.376 & $0.191[-0.196,0.527]$ & 0.330 \\
\hline \multicolumn{5}{|c|}{ Relative total leg bone length } \\
\hline Femur + Tibia & $-0.016[-0.387,0.359]$ & 0.935 & $0.040[-0.338,0.407]$ & 0.841 \\
\hline \multicolumn{5}{|c|}{ Ratio between leg bone lengths } \\
\hline Tibia/Femur & $-0.017[-0.388,0.358]$ & 0.932 & $0.445[0.086,0.702]$ & 0.018 \\
\hline
\end{tabular}

International Amateur Athletic Federation scores, based on the personal best times of each event for 100-m and 400-m specialized sprinters were used as parameters for sprint performance. Italic values indicate a significant correlation $(P<0.05)$ between leg bone length variable and sprint performance in 400 -m specialized sprinters

sprint performance in sprinters $[1,3,7]$. When having a higher ratio of the tibial length to femoral length in $100-\mathrm{m}$ sprinters, this morphology may be modeling smaller thigh muscles due to a necessary shortening of the thigh length. Therefore, the ratio between the leg bone lengths may not relate to $100-\mathrm{m}$ sprint performance in 100-m specialized sprinters.

We previously reported using MRI that relative lengths of the leg bones (i.e., tibial length and total length of the femur and tibia) normalized to body height correlated with running performance in endurance runners [14]. By contrast, in the present study, absolute and relative individual and total lengths of the leg bones did not correlate with sprint performance in either $100-\mathrm{m}$ or 400-m sprinters. Although the longer leg is associated with an increase in step length during sprinting $[9,10]$, step length may be a less important kinematic factor for superior sprint performance than step frequency during both $100-\mathrm{m}$ and 400-m sprinting [15-17]; specifically, an increase in step length is not required for achieving superior sprint performance. Only one study by Morin et al. [15] reported that relative length of the leg (i.e., the distance from the great trochanter to the ground) normalized to body height did not correlate with 100-m sprint velocity. Therefore, the present findings corroborate with this result by showing an absence of a relationship between the leg length and sprint performance in 100-m specialized sprinters. Furthermore, the present study is the first to determine that longer leg may not be required for achieving superior long sprint performance in $400-\mathrm{m}$ specialized sprinters.
This study showed that all bone length variables did not differ between 100-m and 400-m sprinters; thus, characteristics of the leg bone length are similar between the two groups. In additional analyses of the present study, absolute total and individual lengths of the femur and tibia in sprinters (a combined group of 100-m and 400-m sprinters) were higher than those in 5000-m endurance runners (e.g., $431.4 \pm 13.9$ vs. $420.8 \pm 20.2 \mathrm{~mm}$ for the femoral length and $358.8 \pm 13.8$ vs. $351.3 \pm 18.2 \mathrm{~mm}$ for the tibial length; $P<0.05$ for both) observed in our previous study [14], which may be due to greater body height for sprinters than that for endurance runners (172.8 \pm 4.0 vs. $169.6 \pm 5.6 \mathrm{~cm}, P=0.01)$. By contrast, relative individual and total lengths of the femur and tibia and a ratio of the tibial length to femoral length did not differ between sprinters and endurance runners $(25.0 \pm 0.4 \mathrm{vs}$. $24.8 \pm 0.7 \%$ of both height for the relative femoral length, $20.8 \pm 0.6$ vs. $20.7 \pm 0.6 \%$ of body height for the relative tibial length, $0.83 \pm 0.02$ vs. $0.84 \pm 0.02 ; P>0.05$ for all). Similar results were also observed for the leg bone length variables between $100-\mathrm{m}$ and $400-\mathrm{m}$ sprinters and endurance runners (data not shown). Therefore, characteristics of the leg bone lengths relative to body size and the ratio between the leg bone lengths may be similar among athletes competing in distances from $100-\mathrm{m}$ to $5000-\mathrm{m}$.

Our previous studies determined that longer forefoot bones and greater knee extensor moment arm correlated with better long sprint performance in 400-m sprinters $[5,6]$. To the best of our knowledge, no other researchers have reported morphological factors for superior long sprint performance in 400-m sprinters. These favorable 
morphological factors of superior 400-m sprint performance obtained in our previous studies are also determinants for achieving superior 100-m sprint performance $[2,4]$. By contrast, a higher ratio of the tibia length to femoral length may be a determinant only of $400-\mathrm{m}$ sprinters. Therefore, the present study is the first to find a specific morphological factor contributing to superior long sprint performance in 400-m specialized sprinters. The information may be helpful to selecting sprint events and understanding individual features in sprinters, particularly in 400-m specialized sprinters.

\section{Limitations}

We hypothesized that a higher ratio of the tibial length relative to femoral length may help achieve superior long sprint performance, potentially by maintaining step frequency and performing economical sprinting in 400-m specialized sprinters. However, we did not measure kinetic (e.g., ground reaction force) and kinematic (e.g., step frequency) data during 400-m sprinting. Further studies are needed to examine the relationships between the leg bone length variables and kinetic and kinematic data during 400-m sprinting.

\section{Abbreviations \\ IAAF: International Amateur Athletic Federation; MRI: Magnetic resonance imaging.}

\section{Acknowledgements}

We are grateful to all subjects who gave of their time and effort to participate in this study.

\section{Authors' contributions}

DT and TS conceived and designed the experiment; DT, TS, MT, TT, YM, HU and $\mathrm{MO}$ performed experiments; DT and TS analyzed data; DT, TS, MT, TT, YM, $\mathrm{HU}$ MO, AN and TI interpreted results of experiments; DT and TS wrote the manuscript; MT MO AN and TI edited and revised manuscript. All authors read and approved the manuscript.

\section{Funding}

There were no specific grants or funding for the present study.

\section{Availability of data and materials}

Data will be provided the corresponding author upon request.

\section{Ethics approval and consent to participate}

This study was approved by the Ethics Committee of Ritsumeikan University (BKC-IRB-2011-009). Informed written consent was obtained from all participants.

\section{Consent for publication}

Not applicable.

\section{Competing interests}

The authors declare that they have no competing interests.

\section{Author details}

${ }^{1}$ Faculty of Sport and Health Science, Ritsumeikan University, 1-1-1 Nojihigashi, Kusatsu, Shiga 525-8577, Japan. ${ }^{2}$ Graduate School of Health and Sport Science, Nippon Sport Science University, Tokyo, Japan. ${ }^{3}$ Research Fellow of Japan Society for the Promotion of Science, Tokyo, Japan.
Received: 29 January 2020 Accepted: 16 June 2020

Published online: 22 June 2020

\section{References}

1. Ema R, Sakaguchi M, Kawakami Y. Thigh and psoas major muscularity and its relation to running mechanics in sprinters. Med Sci Sports Exerc. 2018;50(10):2085-91.

2. Miyake Y, Suga T, Otsuka M, Tanaka T, Misaki J, Kudo S, Nagano A, Isaka T. The knee extensor moment arm is associated with performance in male sprinters. Eur J Appl Physiol. 2017;117(3):533-9.

3. Sugisaki $\mathrm{N}$, Kobayashi $\mathrm{K}$, Tsuchie $\mathrm{H}$, Kanehisa H. Associations between individual lower-limb muscle volumes and 100-m sprint time in male sprinters. Int J Sports Physiol Perform. 2018;13(2):214-9.

4. Tanaka T, Suga T, Otsuka M, Misaki J, Miyake Y, Kudo S, Nagano A, Isaka T. Relationship between the length of the forefoot bones and performance in male sprinters. Scand J Med Sci Sports. 2017;27(12):1673-80.

5. Tomita D, Suga T, Tanaka T, Ueno H, Miyake Y, Otsuka M, Nagano A, Isaka T. A pilot study on the importance of forefoot bone length in male 400-m sprinters: is there a key morphological factor for superior long sprint performance? BMC Res Notes. 2018;11:583.

6. Tomita D, Suga T, Ueno H, Miyake Y, Otsuka M, Terada M, Nagano A, Isaka T. Relationship between knee extensor moment arm and long-sprint performance in male 400-m sprinters. TransI Sports Med. 2018;1:172-9.

7. Tottori N, Suga T, Miyake Y, Tsuchikane R, Otsuka M, Nagano A, Fujita S, Isaka T. Hip flexor and knee extensor muscularity are associated with sprint performance in sprint-trained preadolescent boys. Pediatr Exerc Sci. 2018;30(1):115-23.

8. Weyand PG, Sternlight DB, Bellizzi MJ, Wright S. Faster top running speeds are achieved with greater ground forces not more rapid leg movements. J Appl Physiol. 2000;89(5):1991-9.

9. Cavanagh PR, Kram R. Stride length in distance running: velocity, body dimensions, and added mass effects. Med Sci Sports Exerc. 1989;21(4):467-79.

10. Paruzel-Dyja M, Walaszczyk A, Iskra J. Elite male and female sprinters' body build, stride length and stride frequency. Stud Phys Culture Tourism. 2006;13(1):33-7.

11. Mackala K. Optimisation of performance through kinematic analysis of the different phases of the 100 metres. New Stud Athlet. 2007;22(2):7-16.

12. Laumets R, Viigipuu K, Mooses K, Mäestu J, Purge P, Pehme A, Kaasik P, Mooses $\mathrm{M}$. Lower leg length is associated with running economy in high level Caucasian distance runners. J Hum Kinet. 2017;56:229-39.

13. Mooses M, Mooses K, Haile DW, Durussel J, Kaasik P, Pitsiladis YP. Dissociation between running economy and running performance in elite Kenyan distance runners. J Sports Sci. 2015;33(2):136-44.

14. Ueno H, Suga T, Takao K, Miyake Y, Terada M, Nagano A, Isaka T. The potential relationship between leg bone length and running performance in well-trained endurance runners. J Hum Kinet. 2019;70:165-72.

15. Morin JB, Bourdin M, Edouard P, Peyrot N, Samozino P, Lacour JR. Mechanical determinants of 100-m sprint running performance. Eur 」 Appl Physiol. 2012;112(11):3921-30.

16. Hobara H, Inoue K, Gomi K, Sakamoto M, Muraoka T, Iso S, Kanosue K. Continuous change in spring-mass characteristics during a $400 \mathrm{~m}$ sprint. J Sci Med Sport. 2010;13(2):256-61.

17. Mann R, Herman J. Kinematic analysis of Olympic sprint performance: men's 200 meters. Int J Sport Biomech. 1985;1 (2):151-62.

18. Otsuka M, Kawahara T, Isaka T. Acute response of well-trained sprinters to a 100-m race: higher sprinting velocity achieved with increased step rate compared with speed training. J Strength Cond Res. 2016;30(3):635-42.

19. Hanon C, Lepretre PM, Bishop D, Thomas C. Oxygen uptake and blood metabolic responses to a 400-m run. Eur J Appl Physiol. 2010;109(2):233-40.

20. Hill DW. Energy system contributions in middle-distance running events. J Sports Sci. 1999;17(6):477-83.

21. de Leva P. Adjustments to Zatsiorsky-Seluyanov's segment inertia parameters. J Biomech. 1996;29(9):1223-30.

22. Ueno H, Suga T, Takao K, Tanaka T, Misaki J, Miyake Y, Nagano A, Isaka T. Association between forefoot bone length and performance in male endurance runners. Int J Sports Med. 2018;39(4):275-81. 
23. Hanon C, Gajer B. Velocity and step parameters of world-class 400-meter athletes compared with less experienced runners. J Strength Cond Res. 2009;23(2):524-31.

24. Slawinski J, Termoz N, Rabita G, Guilhem G, Dorel S, Morin JB, Samozino P. How 100-m event analyses improve our understanding of worldclass men's and women's sprint performance. Scand J Med Sci Sports. 2017;27(1):45-54

\section{Publisher's Note}

Springer Nature remains neutral with regard to jurisdictional claims in published maps and institutional affiliations.
Ready to submit your research? Choose BMC and benefit from:

- fast, convenient online submission

- thorough peer review by experienced researchers in your field

- rapid publication on acceptance

- support for research data, including large and complex data types

- gold Open Access which fosters wider collaboration and increased citations

- maximum visibility for your research: over 100M website views per year

At BMC, research is always in progress.

Learn more biomedcentral.com/submissions 